\title{
PEMETAAN POTENSI BENCANA LONGSOR DI KELURAHAN KEMBANG ARUM
}

\author{
Widjonarko ${ }^{a}$, H.B.Wijaya ${ }^{b}$ \\ aUniversitas Diponegoro, Indonesia, email: widjonarko39@gmail.com \\ ${ }^{b}$ Universitas Diponegoro, Indonesia, email: holibinawijaya@yahoo.com
}

\section{Article Info;}

Received:

22 September 2014

in revised form:

24 September 2014

Accepted:

26 September 2014

Available Online:

1 Oktober 2014

\section{Keywords:}

Mapping, Landslide hazard

Info Artikel;

Diterima:

22 September 2014

Hasil Revisi :

24 September 2014

Disetujui:

26 September 2014

Publikasi On-Line:

1 October 2014

Kata kunci:

Pemetaan, Bencana

longsor

\begin{abstract}
Disaster is a real fact that sometimes less get the full attention by both government and society. This is reflected from the hustle bustle of activity that occurs after the disaster compared with efforts to minimize the impact of disasters. Coexist with a culture of disaster has not become either by the government or the public. And if you are able mendudukan proportionally about the disaster in everyday life, the risk of a disaster will be minimized by itself. One push to institutionalize a culture coexist with disaster is to drive the community to better identify more closely the potential disaster that is around them, one of which is to encourage people to be able to map out the potential disaster in the environment around them.

Kembang Arum Society in general does not fully know and understand the potential and landslide conditions in their neighborhood. Community knew after the collapse of the of a cliff retaining embankments. People were not so attentive to activities pengeprasan hills that surround them. This situation in the long run will further add to the high risk of landslides in the area of the Village of Flower Arum, especially in areas with morphology hills and steep slopes.
\end{abstract}

\begin{abstract}
Abstrak: Kebencanaan merupakan satu fakta riil yang terkadang kurang mendapatkan perhatian penuh baik oleh pemerintah maupun masyarakat. Kondisi ini tercermin dari begitu hiruk pikuknya kegiatan pasca bencana terjadi dibanding dengan upaya untuk meminimasi dampak akibat bencana. Hidup berdampingan dengan bencana belum menjadi satu budaya baik oleh pemerintah ataupun masyarakat. Padahal jika mampu mendudukan secara proporsional tentang kebencanaan dalam kehidupan sehari-hari maka resiko bencana akan dapat diminimalisir secara sendirinya. Salah satu mendorong melembagakan budaya hidup berdampingan dengan bencana adalah mengajak masyarakat untuk lebih mengenali secara lebih dekat potensi kebencanaan yang ada di sekitar mereka, salah satunya adalah mendorong masyarakat untuk dapat memetakan potensi kebencanaan yang ada di lingkungan sekitar mereka.

Masyarakat Kembang Arum secara umum tidak sepenuhnya mengetahui dan paham potensi dan kondisi bencana longsor yang ada di sekitar tempat tinggal mereka. Masyarakat tahu setelah ada kejadian longsor seperti runtuhnya talud penahan tebing. Masyarakat juga tidak begitu perhatian terhadap kegiatan-kegiatan pengeprasan bukit yang ada di sekitar mereka. Keadaan ini dalam jangka panjang akan semakin menambah tinggi resiko bencana longsor di wilayah Kelurahan Kembang Arum, khususnya pada wilayah dengan morfologi perbukitan dan lereng yang curam.
\end{abstract}

\section{PENDAHULUAN}

Kondisi fisik suatu wilayah akan mempengaruhi karakteristik lahan yang ada. Indonesia sebagai wilayah yang mempunyai topografi beragam mempunyai potensi kebencanaan yang berbeda-beda pula. Berdasarkan data yang terdapat pada Badan Nasional Penanggulangan Bencana (BNPB), selama bulan Januari 2014 telah terjadi sekitar 182 kejadian bencana di berbagai wilayah di Indonesia, mulai dari banjir, tanah longsor, angin puting beliung, hingga letusan gunung api. Hal ini membuktikan begitu besarnya ancaman bencana bagi kehidupan masyarakat di Indonesia terutama yang tinggal di daerah rawan 
bencana. Sebanyak 95\% lebih merupakan bencana hidrometeorologi seperti banjir, tanah longsor, dan angin puting beliung, dengan korban jiwa banyak disebabkan oleh bencana banjir dan tanah longsor.

Bencana alam yang terjadi hampir di setiap di wilayah Indonesia adalah bencana banjir dan tanah longsor, dan diperkirakan ancaman banjir dan longsor masih akan terus berlanjut hingga Maret 2014. Bencana longsor banyak terjadi di berbagai wilayah karena sekitar $45 \%$ luas lahan di Indonesia adalah lahan pegunungan berlereng yang peka terhadap longsor dan erosi. Namun demikian faktor kelerengan bukanlah satu-satunya penyebab longsor, karena selain faktor alam yang juga dipengaruhi oleh curah hujan dan geologi, laju infiltrasi, dan penutup lahan, faktor manusia juga mempunyai andil dalam terjadinya longsor.

Tanah longsor adalah suatu peristiwa geologi dimana terjadi pergerakan permukaan tanah (Crozier, 1999) seperti jatuhnya bebatuan atau gumpalan besar tanah. Peristiwa tanah longsor atau dikenal sebagai gerakan masa tanah, bebatuan, atau kombinasinya, sering terjadi pada lereng-lereng alam maupun buatan, dan sebenarnya merupakan suatu fenomena alam. Terjadinya longsor merupakan suatu kondisi dimana alam mencari keseimbangan baru akibat adanya gangguan atau faktor-faktor yang mempengaruhinya dan menyebabkan terjadinya pengurangan gaya geser serta peningkatan tegangan geser. Dengan terjadinya longsor tersebut tentunya dapat mengancam dan mengganggu kehidupan dan penghidupan masyarakat, dan dapat mengakibatkan timbulnya korban jiwa manusia, kerusakan lingkungan, kerugian harta benda, dan dampak psikologis.

Berkaitan dengan hal tersebut diperlukan adanya mitigasi bencana yang merupakanserangkaian upaya untuk mengurangi risikobencana, baik melalui pembangunan fisik maupunpenyadaran dan peningkatan kemampuan menghadapiancaman bencana. Untuk mendukung upaya tersebut tentunya diperlukan informasi mengenai daerah atau lokasi yang rawan longsor yang dapat dibangun melalui sistem informasi geografis dengan melibatkan peran serta masyarakat sebagai pihak yang terkena dampak dalam memberikan informasi terkait dengan lokasi-lokasi longsor serta sejauhmana dampak longsor mereka rasakan.

Kecamatan Semarang Barat Kota Semarang, merupakan daerah yang memiliki kondisi tanah dengan kestabilan yang bervariasi dan topografi yang beragam. Salah satu wilayah kelurahan di Kecamatan Semarang Barat yang mempunyai potensi cukup besar terhadap terjadinya bencana longsor adalah Kelurahan Kembangarum.

Kelurahan Kembangarum memiliki kelerengan datar hingga curam. Wilayah Kelurahan Kembangarum yang bertopografi datar (0-8\%) yaitu pada RW.II, III, IV, untuk wilayah yang bertopografi landai (2-15\%) berada pada RW.I. V, VI, VII, IX, dan XIII, sedangkan wilayah yang bertopografi bergelombang/agak curam (15-25\%) berada di wilayah RW.VIII, XI, dan XII, dan wilayah yang bertopografi curam (25-40\%) RW X dan sebagian kecil RW XIII.

Kondisi tersebut mengakibatkan sebagian wilayahnya rentan terhadap bahaya longsor. Dengan adanya kemungkinan terjadinya bencana longsor tersebut maka perlu adanya pemetaan terhadap lokasi yang rawan longsor sehingga sedapat mungkin dapat meminimalkan dampak yang nantinya mungkin terjadi. Masyarakat sebagai pihak yang paling besar terkena dampak, dilibatkan dalam penentuan lokasilokasi yang paling sering terjadi longsor. Selain itu juga penggunaan Sistem Informasi Geografis dapat digunakan untuk mengidentifikasi kawasan rawan bencana longsor, terutama terkait dengan kondisi fisik wilayah yang ada.

\section{DATA DAN METODE}

Dalam penelitian ini digunakan data yang sifatnya kuantitatif yaitu berupa informasi mengenai karakteristik fisik kawasan yang diperkirakan akan memberikan kontribusi terhadap kejadian longsor di Kelurahan Kembang Arum. Selain itu dibutuhkan juga data yang bersifat kualitatif yang merupakan hasil pemetaan terhadap pemahaman dan pengetahuan masyarakat Kembang Arum terkait bencana longsor di Kelurahan Kembang Arum. Gambaran lebih jelas mengenai kondisi fisik Kelurahan Kembang Arum dapat diikuti pada uraian berikut.

Kelurahan Kembangarum, Kecamatan Semarang memiliki luas lahan 17.464,25 Ha, berbatasan dengan Kelurahan Kalipancur, Purwoyoso, Krapyak (Ngaliyan) dan Kelurahan Kalibanteng Kidul, Kalibanteng Kulon, Manyaran Semarang Barat (lihat gambar). Sebagian besar lahan pada wilayah Kelurahan Kembang 
Arum merupakan kawasan permukiman, baik kawasan perumahan, aktivitas perdagangan dan jasa skala lingkungan. Aktivitas yang terjadi di Kelurahan Kembangarum sudah cukup maju, hal tersebut terlihat dari adanya perkantoran, pendidikan, dan aktivitas perindustrian. Jenis penggunaan lahan di Kelurahan Kembang Arum terdiri dari permukiman, fasilitas kesehatan, fasilitas pendidikan, industri, perkantoran, kawasan militer dan campuran. Dari luas lahan total kelurahan ini, tata guna lahan yang mendominasi adalah permukiman. Adapun jenis penggunaan lahan di Kelurahan Kemban Arum selengkapnya dapat diikuti pada tabel berikut.

Tabel 1. Jenis Penggunaan Lahan Kelurahan Kembang Arum (Peta Citra Kota Semarang, 2012)

\begin{tabular}{clcc}
\hline $\mathbf{1}$ & Permukiman & 16055,38 & 91,93283 \\
$\mathbf{2}$ & Fasilitas Kesehatan & 36,70 & 0,210144 \\
$\mathbf{3}$ & Fasilitas Pendidikan & 159,06 & 0,910775 \\
$\mathbf{4}$ & Industri & 43,70 & 0,250225 \\
$\mathbf{5}$ & Perkantoran & 24,47 & 0,140115 \\
$\mathbf{6}$ & Markas Satbrimob & 952,66 & 5,454915 \\
$\mathbf{7}$ & Campuran & 192,28 & 1,100992 \\
& Jumlah & 17464,25 & 100 \\
\hline
\end{tabular}

Morfologi kawasan merupakan kombinasi antara perbukitan dan dataran dengan ketinggian antara 0-200mdpl. Dari hasil observasi terhadap bentuk muka bumi, Kelurahan Kembangarum terdiri atas dataran dengan klasifikasi relief berdasarkan beda elevasinya yang bervariasi mulai dari ketinggian 0-50 m (hampir datar) berada di RW. RW.II, III, IV, ketinggian 5-50 m (Bergelompang lemah/landai) berada di RW.I. V, VI, VII, IX, dan XIII. ketingian 25-75 m ( bergelombang kuat/miring) RW.VIII, XI, dan XII, ketinggian 50-200m (Berbukit bergelombang) berada di RW X dan sebagian kecil RW XIII. Pola morfologi berupa perbukitan dan dataran berimplikasi pada pola kelerengan di wilayah Kelurahan Kembang Arum. Sebagian besar wilayah Kelurahan Kembang Arum memiliki kelerengan landai. Tipe lereng curam pada wilayah Kelurahan Kembang Arum terdapat pada sebagian kecil wilayah Kelurahan Kembang Arum.

Gambar 1. Kenampakan Permukaan Bumi (Morfologi) Kelurahan Kembang Arum (Interpolasi Peta Kontur Kota Semarang dengan menggunakan global mapper, 2014)

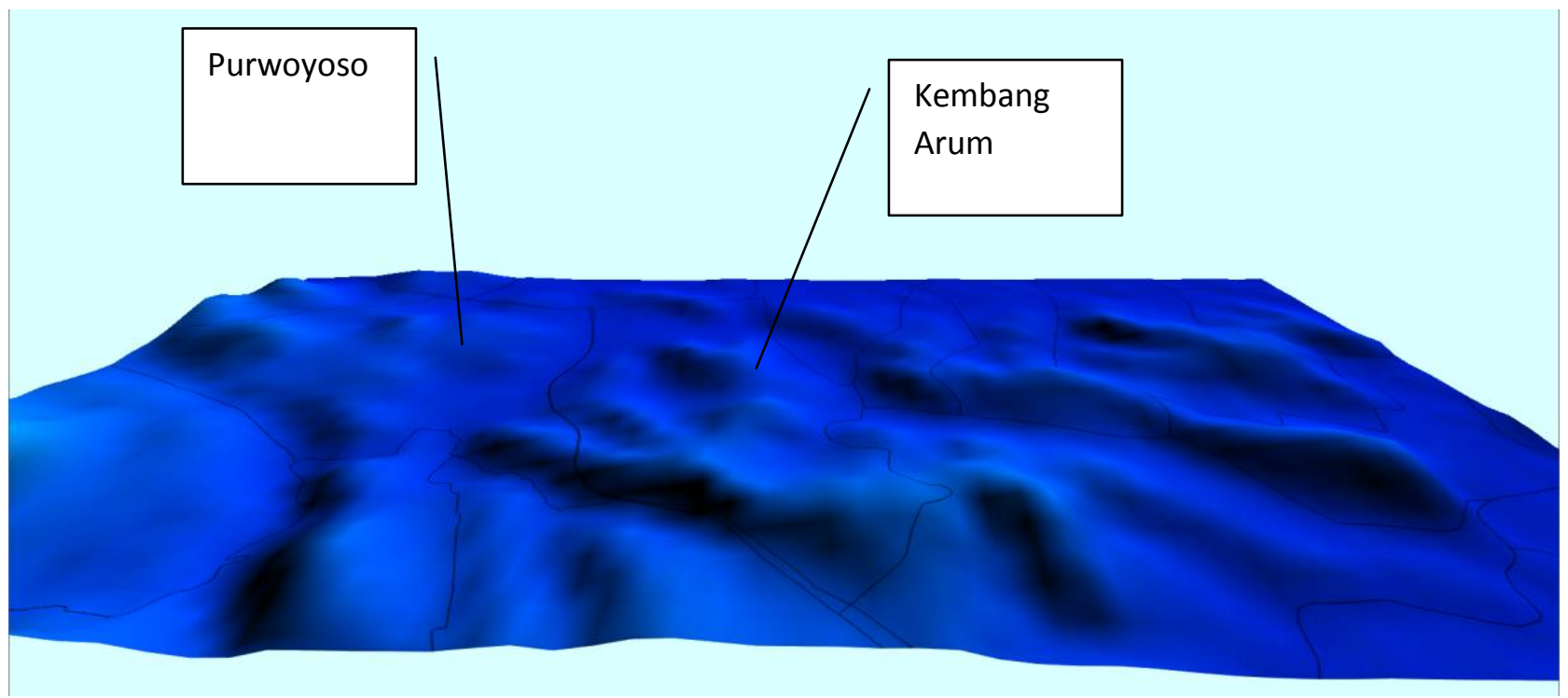


Kelurahan Kembangarum terletak pada kelerengan yang bervariasi diantaranya lereng datar (2-15\%), landai (15-25\%), dan lereng curam (25-40\%). Kelerengan curam (25-40\%) menyebabkan wilayah Kelurahan Kembang Arum temasuk kedalam wilayah yang rawan dengan bahaya longsoran.Berdasarkan kondisi kelerengan Kelurahan Kembangarum tersebut maka Kelurahan ini termasuk dalam wilayah yang rawan bencana alam berupa gerakan tanah menengah dan gerakan tanah rendah. Selain itu Kelurahan ini juga memiliki curah hujan yang cukup tinggi yaitu $27,7-34,8 \mathrm{~mm} /$ hari yang menjadi salah satu faktor terjadinya bahaya geologi. Sedangkan jenis tanah yang untuk kelurahan Kembangarum sendiri terdiri dari jenis tanah Asosiasi Aluvial Kelabu, dan Mediteran Coklat Tua.

Gambar 2. Jenis Tanah dan Kelerengan di Kelurahan Kembang Arum

(Bappeda Kota Semarang dan Interpolasi Kontur 2m)

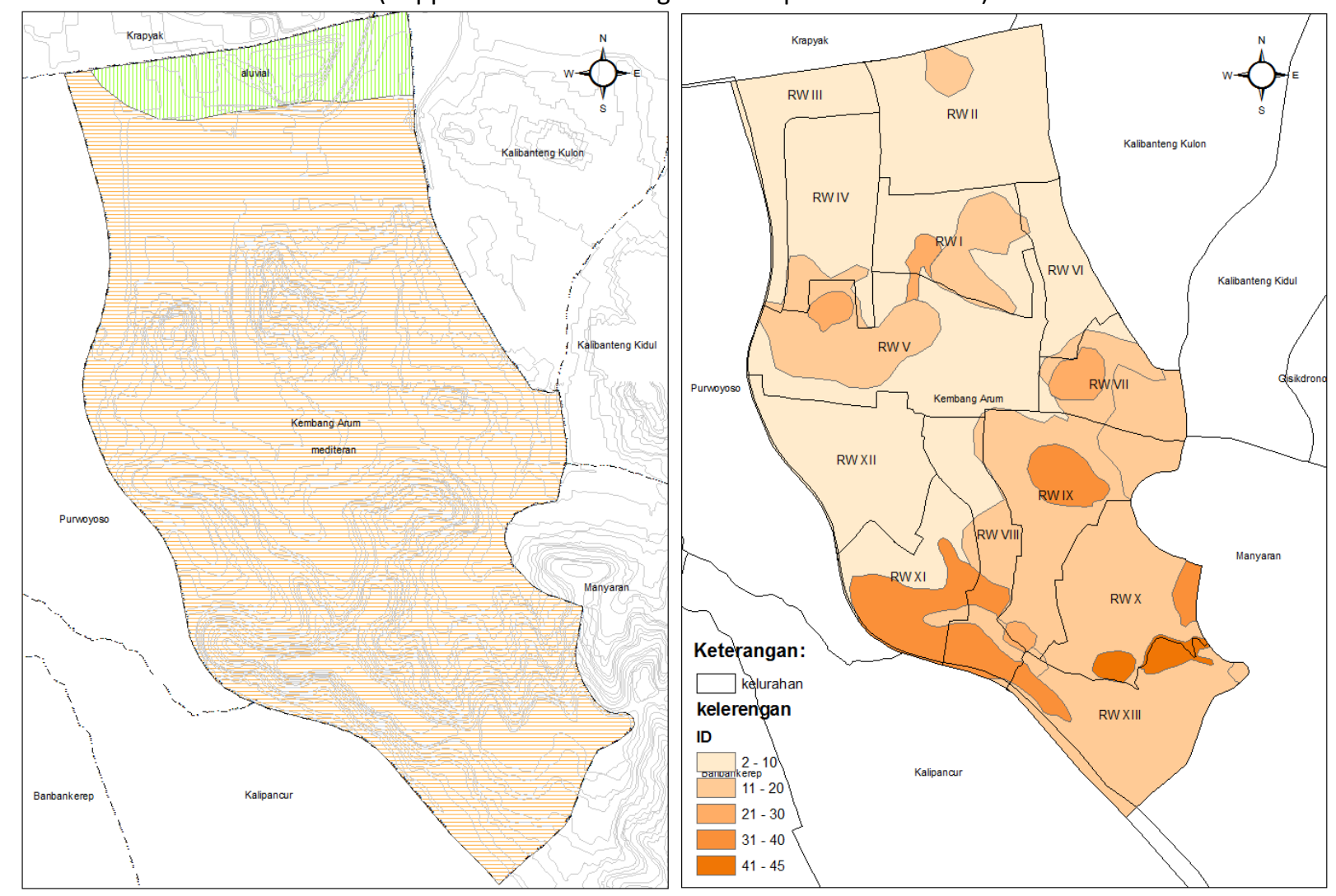

\section{HASIL DAN PEMBAHASAN}

\subsection{Lokasi Rawan Longsor dan Faktor Penyebabnya}

Berdasarkan pada hasil survai lapang dan penggalian informasi melalui penduduk yang tinggal di Kelurahan Kembang Arum didapat satu fakta bahwa pada beberapa lokasi di Kelurahan Kembang Arum memiliki satu kerawanan yang cukup tinggi akan bahaya tanah longsor. Berdasarkan pada hasil verifikasi lapang, terdapat beberapa daerah di Kelurahan Kembang Arum yang mengalami longsor diantaranya adalah RW I, IX, XI dan XII (lihat gambar 3).

Dari ke empat lokasi yang rawan longsor di Kelurahan Kembang Arum ke empatnya memiliki karakteristik longsor yang berbeda-beda. Seperti contoh di RW IX, bencana longsor lebih diakibatkan kepada jenis konstruksi dan pondasi bangunan yang kurang kuat, sehingga frekuensi kejadian longsornya pun tidak dapat diperkirakan dalam rentang waktu tertentu. Sedangkan dibeberapa tempat lebih dikarenakan oleh curah hujan yang terlalu tinggi sehingga frekuensi longsor pun dapat diprediksikan terjadi dalam waktu-waktu tertentu (musim penghujan).Dampak yang diakibatkan juga berbeda-beda dari setiap RW yang diidentifikasi rawan akan longsor. Dampak longsor di RW IX tidak begitu parah apalagi sampai menimbulkan korban jiwa, kebanyakan dampak dari longsor yang berada di RW IX sifatnya lebih ke personal yaitu, dampak hanya dirasakan kepada pemilik rumah yang mengalami longsor tersebut. 
Bencana longsor di Kelurahan Kembang Arum merupakan peristiwa geologi yang terjadi karena pergerakan masa batuan atau tanah dengan berbagai tipe dan jenis seperti jatuhnya bebatuan atau gumpalan besar tanah. Longsor yang ada di Kelurahan Kembang Arum memiliki 2 faktor penyebab, yaitu faktor internal dan faktor eksternal. Yang merupakan faktor internal meliputi kondisi fisik alam seperti topografi yang curam yaitu $25-45 \%$ atau $>45 \%$, kondisi tanah yang peka terhadap erosi dan rawan longsor yaitu jenis tanah alluvium dan mediteran (lihat gambar 2), beserta curah hujan yang tinggi yaitu rata rata $37 \mathrm{~mm} / \mathrm{jam}$.

Faktor eksternal terjadinya longsor di Kelurahan Kembang Arum meliputi kontruksi bangunan yang buruk dan juga cara pengaliran air hujan atau jaringan drainase yang kurang memadai. Seperti yang diketahui daerah dengan topografi tinggi yaitu $25-45 \%$ dan $>45 \%$ tidak diperkenankan sebagai lahan terbangun. Adapun yang tetap digunakan sebagai lahan terbangun seharusnya menggunakan konstruksi dan pondasi yang menyesuaikan ketinggian tanah, akan tetapi di Kelurahan Kembang Arum masih banyak dijumpai bangunan yang berada pada lokasi tersebut yang belum menggunakan konstruksi dan pondasi yang sesuai, sehingga tidak mampu menopang bangunan secara kuat.

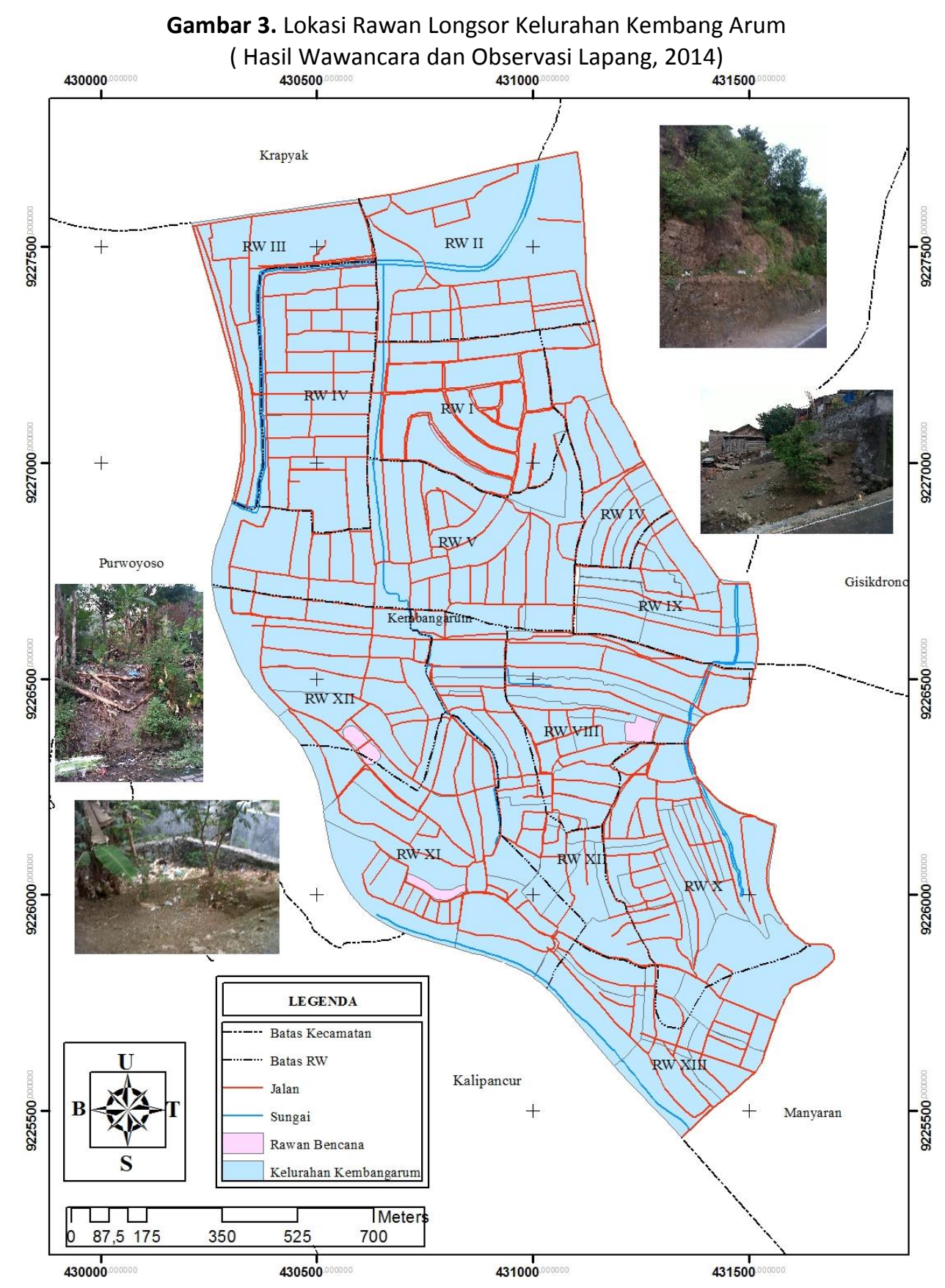




\subsection{Pengetahuan Masyarakat Tentang Bencana Longsor}

Pengetahuan masyarakat terhadap karakteristik lingkungan yang dijadikan tempat tinggal erat kaitannya dengan pemahaman masyarakat terhadap lingkungan tempat tinggalnya. Seperti yang diungkapkan Yunus (2010), bahwa perilaku manusia (behavior) dipengaruhi yang melekat pada dirinya atau factor internal seperti pengetahuan, pengalaman, dan pendidikan.

Dari definisi pengetahuan terhadap lingkungan di atas dapat dijadikan dasar untuk mengidentifikasi tingkat pengetahuan masyarakat Kembang Arum akan bencana longsor. Tingkat pengetahuan masyarakat akan bencana longsor, terutama bagi masyarakat yang tinggal dilokasi rawan longsor masih tergolong rendah. Hal tersebut dapat diketahui dari sebagian besar masyarakat yang tidak mengetahui akan bencana longsor yang ada di daerah yang mereka tinggali. Rata-rata masyarakat belum begitu menyadari bahwa daerah yang mereka tempati sebenarnya rawan akan longsor karena mayoritas dari mereka meyakini bahwa daerah yang mereka tempati tidak rawan longsor. Hal yang melatar belakangi keyakinan masyarakat sekitar bahwa daerah yang mereka jadikan tempat tinggal tidak rawan longsor adalah melihat kondisi jenis tanah padas yang memiliki struktur kuat, sehingga warga berkeyakinan bahwa daerah yang mereka tempati aman dan bebas dari longsor.

Gambar 4. Pengeprasan Bukit Pada Wilayah Kembang Arum

(Hasil Wawancara dan Observasi Lapang, 2014)

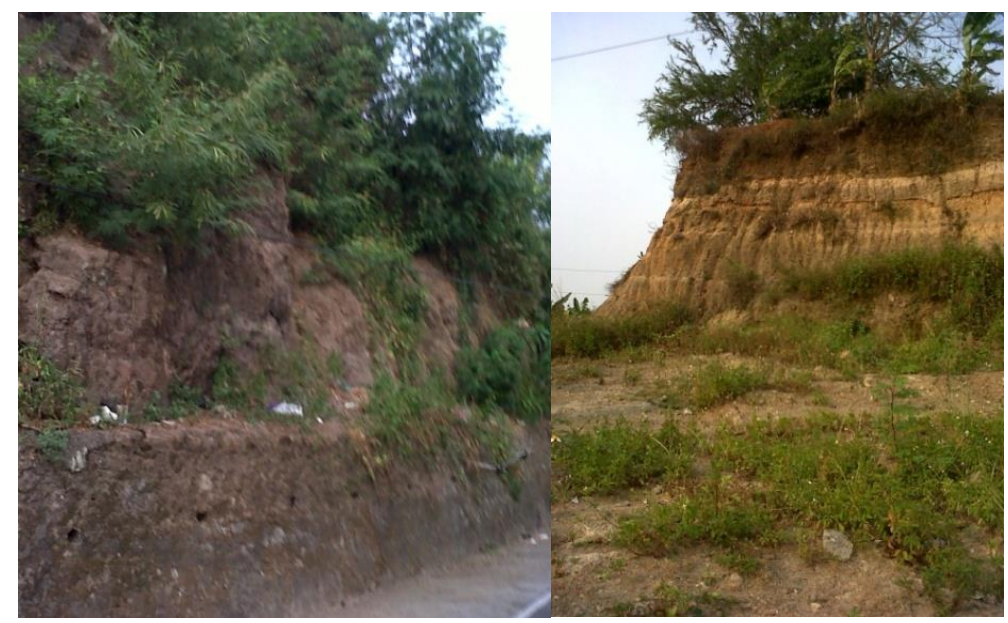

Namun ada pula masyarakat yang belum mengetahui apa definisi longsor. Masyarakat tidak mengetahui bahwa daerah yang mereka tempati rawan akan longsor. Masyarakat hanya mengetahui bahwa ada waktu-waktu tertentu dimana sebagian tanah turun ke permukaan yang lebih rendah yang merupakan dampak dari air hujan.

Meskipun demikian terdapat pula beberapa masyarakat yang sebenarnya mengetahui bahwa daerah yang mereka tempati merupakan rawan longsor, akan tetapi mereka lebih memilih tinggal di daerah tersebut lebih dikarenakan tidak ada pilihan lain. Hal ini merupakan salah satu dampak dari keterbatasan lahan sehingga membuat harga lahan yang semakin tinggi. Sehingga masyarakat tetap bertahan untuk tinggal, walaupun dengan resiko keselamatan yang membahayakan.

Secara umum persepsi merupakan pandangan sesorang terhadap suatu hal. Terdapat dua cara pendekatan untuk memahami suatu presepsi. Pertama adalah pandangan konvensional. Pandangan konvensional menganggap presepsi sebagai kumpulan penginderaan, aktivitas kognisi, member penilaian dan pemaknaan. Pendekatan kedua adalah pandangan holistic. Pandangan kedua berpendapat bahwa presepsi muncul secara spontan dan langsung. Hal ini dikarenakan orgsanisme selalu mengeksplorasi linbgkungan dan melibatkan setiap objek yang ada di lingkungannya (Fisher dkk, 1984; Sarwono, 1992).

Berdasarkan hasil wawancara kepada masyarakat di sekitar rawan longsor, diketahui masyarakat sekitar rawan longsor sebagian besar tidak berkenan untuk berpindah dari tempat yang telah mereka tempati. Hal ini seperti yang disampaikan salah seorang informan yang berada di sekitar rawan longsor: 
"tidak ada rencana mau pindah kecuali anak-anak. Kalaupun ada longsor ya biarkan saja itu kan kehendak Tuhan"

Lebih lanjut, persepsi yang muncul mengenai longsor oleh seorang warga yang bertempat tinggal disekitar daerah rawan longsor seperti yang diungkapkan pada kalimat di bawah ini :

"di sini masalah longsor itu gak ada ya mbak adapun terjadi longsor itu kesalahan manusianya yang kurang tepat mengatur airnya, seperti rumah atas itu sebenarnya kalu menata airnya lewat jalur sebenarnya gak longsor itu air dari genteng atas langsung ke bawah dan dipondasinya itu kan gak diplester. Belum ada longsor kalau dari alam ya itu tadi terjadi longsor karena kesalahan manusia sendiri."

Dari beberapa argumentasi yang disampaikan masyarakat dan korban longsor, mereka beranggapan bahwa mereka tidak mengetahui jika wilayah yang mereka tempati adalah daerah rawan longsor. Yang mereka ketahui adalah ketika terjadi longsoran tanah itu merupakan akibat dari pondasi rumah yang kurang kuat dan gerusan air hujan.

Berdasarkan pengetahuan dan persepsi masyarakat pada kawasan rawan longsor dapat pula diidentifikasi pola-pola adaptasi masyarakat Kelurahan Kembang Arum dalam mengantisipasi kejadian longsor. Bentuk-bentuk adaptasi masyarakat adalah dalam bentuk adaptasi secara fisik, yaitu melakukan perbaikan konstruksi bangunan dan juga melakukan perkuatan tebing pada wilayah perbukitan yang rentan longsor. Kemampuan adaptasi masyarakat Kembang Arum sangat dipengaruhi oleh kemampuan finansial masyarakat. Secara kebetulah pada kawasan-kawasan yang sering mengalami kejadian longsor kemampuan finansial masyarakat cenderung rendah, sehingga bentuk adaptasi untuk meminimalkan resiko longsor dapat dikatakan rendah.

\subsection{Analisis Resiko Bencana Longsor Pada Kelurahan Kembang Arum}

Secara fisik, Kelurahan Kembang Arum memiliki potensi yang cukup tinggi terhadap bencana longsor. Perilaku masyarakat yang mengubah bentang alam dengan melakukan pengeprasan bukit dan bermukim pada daerah dengan kelerengan curam menambah tinggi potensi bencana longsor di Kelurahan Kembang Arum.

Beberapa kawasan yang memiliki potensi longsor yang tinggi antara lain wilayah RW VIII, IX, X, XII dan XIII (Warna Merah). Sedangkan lokasi yang memiliki potensi longsor sedang adalah wilayah RW I, IV, V, VII, VIII, IX, X, XII dan XIII. Hasil perhitungan dengan menggunakan metode pembobotan ini tidak jauh berbeda dengan hasil observasi dan wawancara yang dilakukan pada masyarakat di Kelurahan Kembang Arum. Hasil simulasi ini mengkonfirmasikan bahwa informasi yang disaring dari masyarakat berkaitan dengan longsor benar adanya.

Gambar 5. Potensi Longsor Akibat Kondisi Fisik Kawasan

(Data diperoleh dari Bappeda Kota Semarang diolah dan dianalisis Tim Penyusun, 2014)

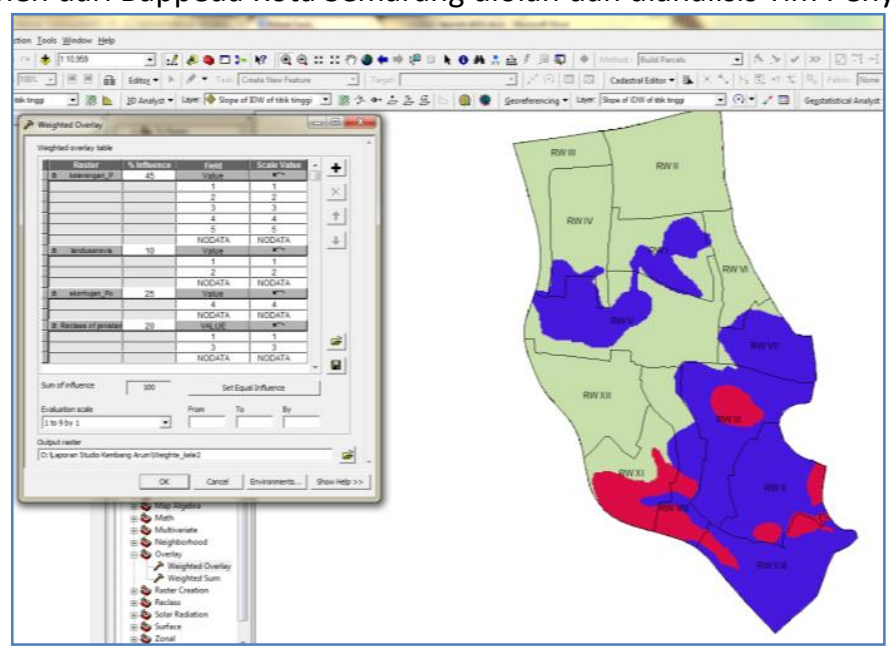


Potensi longsor akan semakin tinggi pada lokasi-lokasi tersebut seiring dengan lemahya kemampuan adaptasi masyarakat Kembang Arum terhadap bencana longsor. Lokasi-lokasi yang berada pada tingkat kerawanan sedang akan menjadi memiliki resiko tinggi karena kemampuan adaptasi masyarakat untuk membuat bangunan pengaman berupa talud tebing adalah rendah. Keadaan ini tentu tidak dapat didiamkan begitu saja oleh Pemerintah Kota Semarang. Sosialisasi dan peningkatan pemahaman masyarakat akan bencana longsor perlu dilakukan secara intensif untuk meningkatkan pengetahuan masyarakat. Selain itu perlu ada upaya bantuan pemerintah untuk melakukan kegiatan perkuatan tebing sesuai dengan kaidah konstruksi agar masyarakat Kembang Arum tidak semakin tentan terhadap resiko bencana.

Tingkat kerentanan ini akan semakin tinggi apabila dilihat dari sudut pandang kepadatan penduduk. Secara kebetulan kawasan yang memiliki potensi longsor tinggi adalah kawasan dengan tingkat hunian yang padat dan sebagian besar adalah bangunan yang tidak/belum memiliki bangunan pengaman talud tebing.

Gambar 6. Kerentanan Longsor Akibat Faktor Kepadatan (Analisis Tim Penyusun, 2012)

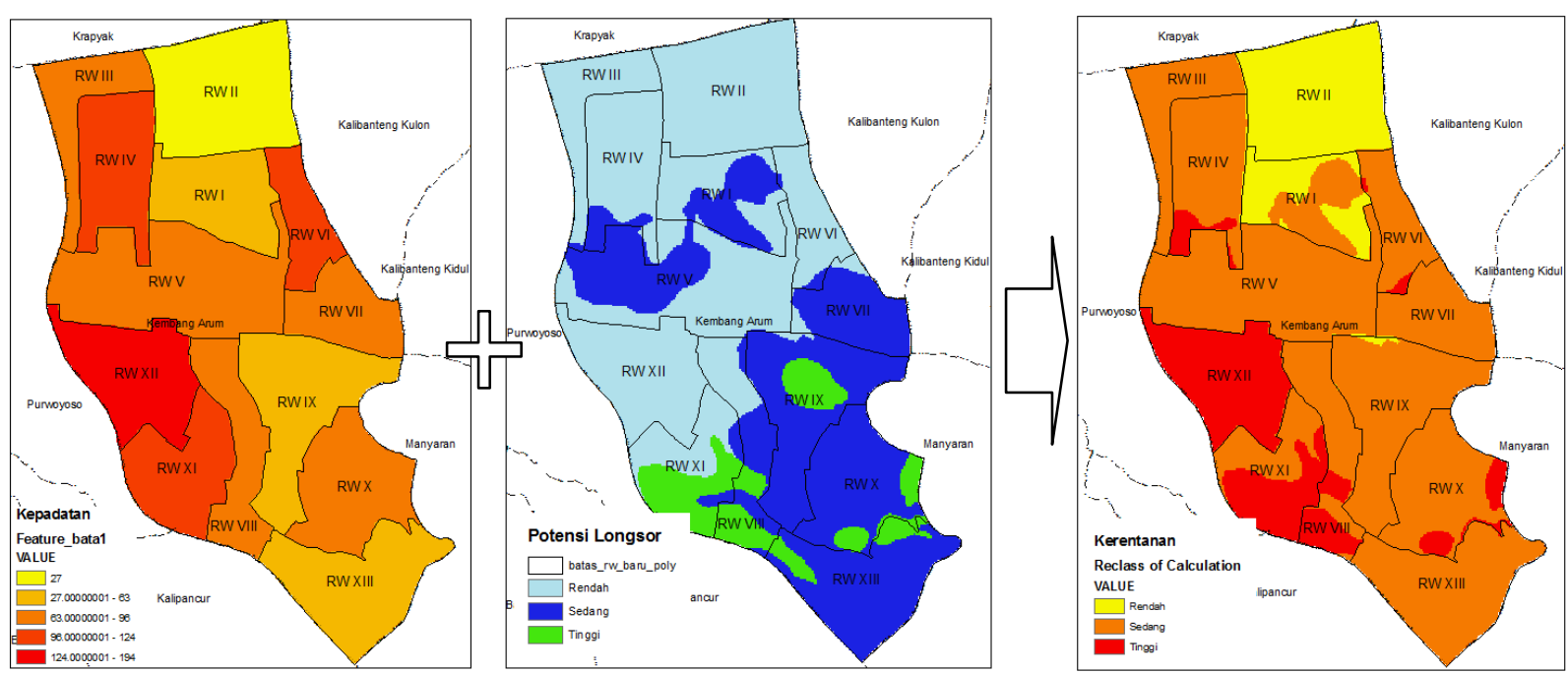

Tingkat kerentanan tinggi ini diakibatkan potensi dampak yang akan semakin besar apabila kejadian longsor terjadi pada kawasan dengan kepadatan penduduk tinggi. Potensi korban akan semakin banyak seiring dengan kepadatan yang tinggi serta pengetahuan serta kemampuan adapatasi yang rendah.

\section{KESIMPULAN}

Berdasarkan pada hasil dapat disimpulkan bahwa masyarakat Kelurahan Kembang Arum belum memiliki pengetahuan yang memadai terhadap potensi bencana longsor di sekitar lingkungan permukiman mereka. Pengetahuan tentang longsor muncul saat ada kejadian bencana longsor di sekitar lingkungan permukiman mereka. Kondisi ini tercipta karena minimnya informasi kebencanaan yang dipublikasikan oleh Pemerintah Kota Semarang. Pengetahuan yang kurang memadai ini harus dihadapkan pada fakta bahwa mereka tidak memiliki kemampuan yang cukup untuk menghindarinya, dikarenakan faktor ekonomi masyarakat. Sebagian besar masyarakat karena kondisi ekonominya pasrah terhadap keadaan. Keinginan untuk terhindar dari bencana dihadapkan pada ketidakmampuan untuk membiayai upaya mitigasi terhadap bencana. Keadaan ini tergambar jelas dari konstruksi rumah pada daerah dengan lereng yang cukup curam yang tidak dilengkapi dengan talud penahan tebih yang memadai.

Keadaan ini akan semakin buruk di masa mendatang apabila upaya untuk mengurangi resiko baik secara individual maupun secara kolektif tidak pernah dapat diwujudkan. Untuk itu Pemerintah Kota Semarang perlu pro aktif untuk mengurangi resiko bencana, melalui upaya sosialisasi dan peningkatan pengetahuan masyarakat terhadap bencana longsor di Kelurahan Kembang Arum. Selain itu Pemerintah 
Kota Semarang juga dibutuhkan untuk memberikan fasilitasi peningkatan kapasitas adaptasi masyarakat Kelurahan Kembang Arum terhadap bencana longsor melalui bantuan teknis dan dana untuk pembangunan pengaman tebing.

Upaya ini penting mengingat banyak kejadian longsor di Kota Semarang yang terjadi sebagai akibat faktor kelalaian para pihak terkait, sebagai contoh longsor di Lempong Sari. Kawasan ini secara geomorfologi dan fisik mirip dengan Kelurahan Kembang Arum. Faktor pembeda adalah pada wilayah tersebut cukup banyak masyarakat yang memiliki kemampuan finansial yang memadai. Meskipun demikian tingkat resiko yang dihadapi masyarakat relatif sama, terutama saat hujan deras yang mengakibatkan longsornya talud tebing yang diatasnya berdiri bangunan milik orang-orang kaya.

\section{DAFTAR PUSTAKA}

Amri, A. 2001. Sistem Informasi Geografis. Makalah disampaikan pada Rapat Kerja SIG Nasional VI, Bandung Arnstein, S.R. 1969. A Ladder of Citizen Participation, Journal of American Institute of Planners, 35(4), 21624.

Asdak, Chay. 2010. Hidrologi dan Pengelolaan Daerah Aliran Sungai. Yogyakarta: Gadjah Mada University Press.

Bakornas PB. 2007 Pengenalan Karakteristik Bencana dan Upaya Mitigasinya di Indonesia. Jakarta: Direktorat Mitigasi

Brahmantyo, B dan Puradimaja, DJ. 2005. Mengenal dan Mengantisipasi Bencana Alam Geologis. Artikel dimuat di JAS edisi DisasterManagement Tahun II No.3/April-Mei-Juni 2005

Brodie, E. and Cowling. 2010. Using participatory mapping to explore participation in three communities. Landscapes of participation: findings and lessons from Community mapping. E. NCVO/VSSN Research Conference

Chambers, R. 2006. 'Participatory mapping and geographic information systems: Whose map? Who is empowered and who disempowered? Who gains and wholoses?'. The Electronic Journal on Information Systems in Developing Countries. EJISDC. 25 (2): 1-11.

Cohen, J. M., and Uphoff, N. 1997. Rural Development Participation: Concepts Measures for Project Design Implementation and Evaluation Inthado, NewYork, Cornell University.

Craig, William.J, Trevor M.Harris,Daniel Weiner. 2002. Community Participation and Geographic Information System. London and New York. CRC Press

Crozier, MJ.1999. Landslides: causes, consequences, and environment. London. Croom Helm.

Dunn, Christine E. 2007. Participatory GIS - a people's GIS?. Journal ofProgress in Human Geography 31(5) . 616-637

Khadiyanto, Parfi. 2007. Partisipasi Masyarakat dalam Pembangunan Unit Sekolah Baru. Semarang: Badan Penerbit Universitas Diponegoro

Mapedza, F., J. Wright, et al. 2003. An Investigation of Land Cover Change in Mafungautsi Forest, Zimbabwe, Using GIS and Participatory Mapping. Applied Geography 12: 1-21.

Moleong, Lexi, J. 1993. Metode Penelitian Kualitatif, Bandung: PT Remaja Rosdakarya

Prahasta, Eddy. 2004. Sistem Informasi Geografis. Bandung: Informatika.

Priyono, Kuswaji Dwi, dkk. 2006. Analisis Tingkat Bahaya Longsor Tanah di Kecamatan Banjarmangu Kabupaten Banjarnegara. Forum Geografi, Vol. 20, No. 2, Desember 2006

Puntodewo, A. dkk. 2003. Sistem Informasi Geografis Untuk Pengelolaan Sumber Daya Alam. Jakarta : Cifor.

Rahim, Supli Effendi. 2000. Pengendalian Erosi Tanah Dalam Rangka Pelestarian Lingkungan Hidup. Bandung: Bumi Aksara.

Sunarto Goenadi, dkk., 2003, Konservasi Lahan Terpadu Daerah Rawan Bencana Longsoran di Kabupaten Kulonprogo Daerah Istimewa Yogyakarta, Laporan Penelitian,Yogyakarta: Lembaga Penelitian UGM.

Suripin. 2002. Pelestarian Sumber Daya Tanah dan Air. Yogyakarta: Penerbit Andi

Vajjhala, Shalini P. 2005. Integrating GIS and Participatory Mapping in Community Development Planning. Paper for the ESRI International User Conference, Sustainable Development andHumanitarian Affairs Track, San Diego, CA.

-------, 2007, Undang-undang Negara Republik Indonesia No 24/2007 tentang Penanggulangan Bencana

-------, 2007, Undang-undang Negara Republik Indonesia No 26/2007 tentang Penataan Ruang. 